\title{
Shen-Kang protects against tacrolimus-induced renal injury
}

\author{
Long Ye Zhang ${ }^{1}$, Jian Jin ${ }^{1,2,3}$, Kang Luo ${ }^{1,2,3}$, Shang Guo Piao', Hai Lan Zheng ${ }^{1}$, Ji Zhe Jin ${ }^{1}$, Sun Woo Lim², \\ Bum Soon Choi ${ }^{2,3}$, Chul Woo Yang ${ }^{2,3}$, and Can Li ${ }^{1}$
}

${ }^{1}$ Department of Nephrology, Yanbian University Hospital, Yanbian, China; ${ }^{2}$ Transplantation Research Center, Department of Internal Medicine, ${ }^{3}$ Convergent Research Consortium for Immunologic Disease, College of Medicine, Seoul St. Mary's Hospital, The Catholic University of Korea, Seoul, Korea

Received: August 7, 2017

Revised : September 19, 2017

Accepted: September 23, 2017

\section{Correspondence to}

Can Li, M.D.

Department of Nephrology, Yanbian University Hospital, \#1327 Juzi St, Yanji 133000, Jilin Prov., Yanbian, China

Tel: +86-188-4333-0302

Fax: +86-433-251-3610

E-mail: lican@ybu.edu.cn
Background/Aims: Evidence suggests that Shen-Kang (SK), a traditional Chinese herbal medicine, protects against various types of renal injury. In this study, we evaluated whether SK treatment confers renoprotection in a rat model of chronic tacrolimus (TAC) nephropathy.

Methods: Rats were treated daily with TAC (1.5 mg/kg, subcutaneously) and SK (450 $\mathrm{mg} / \mathrm{kg}$, intravenously) for 4 weeks. The effects of SK on TAC-induced renal injury were assessed by measuring renal function, urine albumin excretion, histopathology, inflammatory cell infiltration, expression of profibrotic (transforming growth factor $\beta 1$ [TGF- $\beta 1]$ and TGF- $\beta$ inducible gene-h3 [ $\beta$ ig-h3]) and proinflammatory cytokines, oxidative stress, and apoptotic cell death.

Results: Administration of SK preserved glomerular integrity (fractional mesangial area and Wilms tumor 1-positive glomeruli), attenuated tubulointerstitial fibrosis, and reduced the number of ectodermal dysplasia 1-positive cells, and this was paralleled by improved urine albumin excretion and renal dysfunction. At the molecular level, SK treatment suppressed expression of TGF- $\beta 1 / \operatorname{Smad} 2 / 3$, $\beta i g-h_{3}$, and proinflammatory cytokines. Oxidative stress and apoptotic cell death were significantly decreased with SK treatment, and apoptosis-related genes were regulated toward cell survival (active caspase-3 and the B-cell lymphoma-2/ Bcl2-associated X [Bcl-2/Bax $]$ ratio).

Conclusions: SK protects against TAC-induced renal injury.

Keywords: Tacrolimus; Shen-Kang; Transforming growth factor beta1; Apoptosis; Oxidative stress

\section{INTRODUCTION}

Tacrolimus (TAC) contributes to be the mainstay of immunosuppressive agents used for the management of multi-organ transplantation rejection and various autoimmune disorders. However, long-term use of TAC is often limited by its adverse side effects relation to diabetes mellitus (DM) and chronic nephropathy [1]. Chronic TAC nephropathy has been reported in up to $20 \%$ of transplant recipients as well as in nontransplant settings [2]. Glomerular injury caused by DM, inflammatory cell infiltration, and striped tubulointerstitial fibrosis (TIF) are characteristic features of this clinical dilemma, which is closely associated with renal dysfunction and proteinuria. Many molecular mechanisms account for chronic TAC nephropathy, and in vivo and in vitro studies have identified inflammatory mediators, transforming growth factor $\beta 1$ (TGF- $\beta 1$ ), oxidative stress, and apoptotic cell death as important factors [3-5].

Shen-Kang (SK) is a traditional Chinese herbal med- 
icine that consists of 4 herbs components: rhubarb (Rheum officinale 16.7\%), red sage(Salvia miltiorrhiza 16.7\%), safflower (Carthamus tinctorius 16.6\%), and astragalus (Astragalus membranaceus 50\%). Because of the biological activities of these herbal components, the clinical use of SK injections has produced a significant reduction in proteinuria and an improvement of renal function in chronic kidney disease patients. Therefore, SK has been applied widely in the treatment of CKD patients in China over several decades. There is overwhelming evidence demonstrating that, through its antifibrotic and antioxidant potential, SK can effectively preserve renal proximal tubule epithelial cell (HK-2 cell) viability, inhibit high-glucose-induced proliferation of renal mesangial cells, and protect against renal lesions [6-8]. The renoprotective effects of SK have also been reported in 5/6 nephrectomy [6,9], streptozotocin (STZ)-induced diabetic nephropathy (DN) [10], and spontaneously hypertensive nephropathy [11]. However, the beneficial effects of SK on TAC-induced nephropathy remain to be explored.

In this context, we aimed to investigate the renoprotective effect of SK in an experimental model of TAC-induced nephropathy.

\section{METHODS}

\section{Experimental design}

The protocol of the experimental study (CUMC-20160101-01) was approved by the animal care committee of the Catholic University of Korea. Male Sprague Dawley rats (Charles River Technology, Seoul, Korea) weighing 200 to $220 \mathrm{~g}$ were housed in individual cases (Nalge Co., Rochester, NY, USA) in a temperature- and light-controlled environment and allowed free access to a lowsalt diet (0.05\% sodium, Teklad Premier, Madison, WI, USA) and tap water. TAC (Prograf, Astellas Pharma, Ibaraki, Japan) was diluted in olive oil (Sigma, St Louis, MO, USA) to a final concentration of $1.5 \mathrm{mg} / \mathrm{mL}$. The SK was kindly provided by the Xi'an Shiji Shengkang Pharmaceutical Industry Co. Ltd. (Xi'an, China).

After acclimatization and a low-salt diet for 1 week, weight-matched rats were randomized into four subgroups and were treated daily for 4 weeks as follows: (1) subcutaneous injection with olive oil (1 mL/kg vehicle
[VH]; $\mathrm{n}=9$ ); (2) simultaneous treatment with olive oil and $\mathrm{SK}$ (450 mg/kg intravenously, $\mathrm{n}=9$ ); (3) subcutaneous injection with TAC (1.5 mg/kg, $\mathrm{n}=9$ ); and (4) simultaneous treatment with TAC and SK $(\mathrm{n}=9)$.

The SK injection was diluted in saline to a final concentration of $450 \mathrm{mg} / \mathrm{mL}$ and administered intravenously via tail vein at a dose of $450 \mathrm{mg} / \mathrm{kg}$. The dosage and route of TAC and SK were based on previous studies $[6,12]$.

\section{Basic parameters}

Rats were pair-fed and their body weight (BW) was monitored daily. After the 4-week treatment period, animals were housed individually in metabolic cages (Tecniplast, Gazzada, Italy), and their water intake and urine volume were measured over 24 hours. On the following day, animals were anesthetized, and blood samples and tissue specimens were obtained for further analysis.

Measurement of urine albumin was performed using enzymatic colorimetric methods (Modular DPP system, Roche, Hamburg, Germany). Serum creatinine (Scr) and blood urea nitrogen (BUN) were measured using a quantitative enzymetic colorimetric method (Stanbio Laboratory, Boerne, TX, USA). Systolic blood pressure (SBP) was recorded in conscious rats by the tail-cuff method with plethysmography using a tail manometer-tachometer system (BP-2000, Visitech system, Apex, NC, USA). At least three readings were averaged for each rat. The whole-blood TAC level was measured using liquid chromatography-tandem mass spectrometry (LC-MS/MS) [13].

\section{Blood glucose level}

Blood glucose level was measured with an intraperitoneal glucose tolerance test (IPGTT) at the end of the 4-week treatment period as described previously, and the area under the curve of glucose (AUCg) was calculated by trapezoidal estimation from the values obtained in the IPGTT [14].

\section{Histopathology}

Kidney specimens were fixed in periodate-lysine-paraformaldehyde solution and embedded in wax. After dewaxing, 4- $\mu \mathrm{m}$ sections were processed and stained with periodic acid-Schiff (PAS) or Masson's trichrome and hematoxylin. Glomerular injury was assessed with mesangial matrix area. The mesangial matrix area was detected in PAS stained sections and semiquantified 
for each glomerular cross-section by a color image auto-analyzer (TDI Scope Eye Version 3.0 for Windows, Olympus, Tokyo, Japan). A finding of TIF was defined as a matrix-rich expansion of the interstitium with tubular dilatation, tubular atrophy, tubular cast formation, sloughing of tubular epithelial cells, or thickening of the tubular basement membrane. A minimum of 20 fields/ sections was assessed using a color image auto-analyzer. Briefly, the image was captured, and the extent of TIF was quantified using the Polygon program by counting the percentage of areas injured per field of cortex under $\times 100$ magnification. Histopathological analyses were performed in randomly selected cortical fields of sections by a pathologist blinded to the identity of the treatment groups [15].

\section{Immunohistochemistry}

After dewaxing, sections were incubated with $0.5 \%$ Triton $\mathrm{X}$ 100/PBS solution for 30 minutes and washed with phosphate buffered saline three times. Non-specific binding sites were blocked with normal horse serum diluted 1:10 in $0.3 \%$ bovine serum albumin for 30 to 60 minutes, and then incubated for 2 hours at $4^{\circ} \mathrm{C}$ in mouse antiserum against osteopontin (OPN, MPIIIBı, obtained from the Developmental Studies Hybridoma Bank, University of Iowa, Iowa City, IA, USA) diluted in 1:1,000 in humid environment. After rinsing in Tris-buffered saline (TBS), sections were incubated in peroxidase-conjugated rabbit anti-mouse immunoglobulin G (Amersham Pharmacia Biotech, Piscataway, NJ, USA) for 30 minutes. For coloration, sections were incubated with a mixture of $0.05 \% 3,3$ '-diaminobenzidine containing $0.01 \% \mathrm{H}_{2} \mathrm{O}_{2}$ at room temperature until a brown color was visible, washed with TBS, counterstained with hematoxylin and examined under light microscopy. The procedure of immunostaining for ectodermal dysplasia 1 (ED-1, AbD Seroec, Oxford, UK), Wilms tumor 1 (WT-1, Santa Cruz Biotechnology, Santa Cruz, CA, USA), angiotensin II (Ang II, Peninsula Labs, San Carlos, CA, USA), cysteinyl aspartate specific proteinase-3 (Caspase-3, Millipore, Billerica, MA, USA), manganese superoxide dismutase (MnSOD, Abcam, Cambridge, MA, USA), and 8-hydroxy-2'-deoxyguanosine (8-OHdG, JaICA, Shizuoka, Japan) was similar to that for OPN. Twenty different random glomeruli was evaluated to present the number of WT-1-positive cells per $\times 1,000$ magnification view, and twenty different fields in each section at $\times 200$ magnification were analyzed using a color image analyzer (TDI Scope Eye Version 3.0 for Windows) [3]. Analysis of Ang II immunostaining was evaluated by counting the number of Ang II-positive juxtaglomerular afferent arterioles per total number of juxtaglomerular afferent arterioles available for examination, using a 20 objective; at least 50 glomeruli (not overlapping) were evaluated per section.

\section{Immunoblotting analysis}

Immunoblotting analyses were performed as previously described [16]. Interleukin-17 (IL-17, Cell signaling Technology, Danvers, MA, USA), TGF- $\beta 1$ (R\&D Systems, Minneapolis, MN, USA), TGF- $\beta$ inducible gene-h3 (ßig-h3, Proteintech, Chicago, IL, USA), MnSOD (Abcam), Smad2/3 (Cell signaling Technology, Danvers, MA, USA), B-cell lymphoma-2 (Bcl-2, Santa Cruz Biotechnology), Bcl2-associated X (Bax, Delta Biolabs, Gilroy, CA, USA), and $\beta$-actin (Sigma) were detected with specific antibodies. Immunoblotting images were analyzed with an image analyzer (Quantity One, Bio-Rad Technical Service Department, Hercules, CA, USA). Optical densities were obtained using the VH group as $100 \%$ reference and normalized with $\beta$-actin.

\section{Measurement of 8-OHdG level}

Oxidative DNA damage was assessed by measuring the level of the DNA adduct 8-OHdG in serum and urine using a competitive enzyme-linked immunosorbent assay (Cell BIOLABS, San Diego, CA, USA).

\section{In situ TdT-mediated dUTP-biotin nick end labeling assay}

Apoptosis in tissue sections was identified using the ApopTag in situ Apoptosis Detection Kit(Millipore). The number of terminal deoxynucleotidyl transferase-mediated dUTP nick-end labeling (TUNEL)-positive cells was counted in 20 different fields in each section at $\times 200$ magnification.

\section{Statistical analysis}

The dates are expressed as mean \pm standard error. Multiple comparisons among groups were fulfilled by oneway analysis of variance with the Bonferroni post hoc test (SPSS software version 19.0, IBM Co., Armonk, NY, USA). 
Table 1. Effect of SK on basic parameters

\begin{tabular}{|c|c|c|c|c|}
\hline Variable & $\mathrm{VH}$ & $\mathrm{VH}+\mathrm{SK}$ & TAC & $\mathrm{TAC}+\mathrm{SK}$ \\
\hline$\Delta \mathrm{BW}, \mathrm{g}$ & $84 \pm 6$ & $81 \pm 11$ & $54 \pm 6^{\mathrm{a}}$ & $57 \pm 3^{\mathrm{a}}$ \\
\hline $\mathrm{UV}, \mathrm{mL} /$ day & $9.1 \pm 2.3$ & $10.1 \pm 1.6$ & $26.0 \pm 3.1^{a}$ & $23.2 \pm 3.5^{\mathrm{a}}$ \\
\hline WI, mL/day & $15 \pm 4$ & $17 \pm 5$ & $30 \pm 3^{\mathrm{a}}$ & $27 \pm 5^{\mathrm{a}}$ \\
\hline UA, mg/day & $9.0 \pm 2.3$ & $8.9 \pm 2.1$ & $29.5 \pm 2.8^{\mathrm{a}}$ & $18.1 \pm 3.5^{\mathrm{b}}$ \\
\hline Scr, mg/dL & $0.35 \pm 0.07$ & $0.27 \pm 0.02$ & $0.64 \pm 0.06^{\mathrm{a}}$ & $0.51 \pm 0.05^{b}$ \\
\hline BUN, mg/dL & $14 \pm 3$ & $13 \pm 1$ & $47 \pm 6^{a}$ & $33 \pm 3^{b}$ \\
\hline SBP, mmHg & $118 \pm 10$ & $120 \pm 9$ & $120 \pm 12$ & $119 \pm 11$ \\
\hline TAC con, ng/mL & - & - & $9.9 \pm 1.4$ & $10.5 \pm 1.7$ \\
\hline
\end{tabular}

Values are presented as mean $\pm \mathrm{SD}$.

SK, Shen-Kang; VH, vehicle; TAC, tacrolimus; $\triangle \mathrm{BW}$, body weight gain; UV, urine volume; WI, water intake; UA, urine albumin; Scr, serum creatinine; BUN, blood urea nitrogen; SBP, systolic blood pressure.

${ }^{\mathrm{a}} \mathrm{p}<0.05$ vs. VH.

${ }^{\mathrm{b}} p<0.05$ vs. TAC.

Statistical significance was accepted as $p<0.05$.

\section{RESULTS}

\section{Effect of SK on basic parameters}

Table 1 shows the effect of SK on basic parameters in the experimental groups. The mean BW of TAC-treated rats was significantly lower than that of $\mathrm{VH}$-treated rats ( $54 \pm 6$ vs. $84 \pm 6, p<0.01$ ). SK treatment did not prevent loss of BW. TAC induced an increase in 24 hours water intake and urine volume compared with the $\mathrm{VH}$ group, whereas these parameters were unaffected by SK treatment. Urine albumin, Scr, and BUN were much higher in the TAC group compared with the VH group, but their levels were significantly decreased by concomitant administration of SK. Four-week TAC treatment led to an increase in blood TAC concentration to a level of 9.9 $\pm 1.4 \mathrm{ng} / \mathrm{mL}$, whereas SK did not influence the level of TAC concentration $(10.5 \pm 1.7 \mathrm{ng} / \mathrm{mL}$ vs. $9.9 \pm 1.4 \mathrm{ng} / \mathrm{mL}$, $p>0.05)$. There were no significant differences among groups for SBP.

\section{Effect of SK on blood glucose in TAC-induced DM}

Chronic TACtreatmentisassociated withinduction ofDM as manifested by increased IPGTT $(578 \pm 40 \mathrm{mg} / \mathrm{dL} / \mathrm{min}$ vs. $357 \pm 35 \mathrm{mg} / \mathrm{dL} / \mathrm{min}, p<0.05)$ and AUCg $(578 \pm 40 \mathrm{mg} /$ $\mathrm{dL} / \mathrm{min}$ vs. $357 \pm 35 \mathrm{mg} / \mathrm{dL} / \mathrm{min}, \mathrm{p}<0.05$ ) when compared with the VH group. However, SK could not decrease the level of IPGTT $(558 \pm 38 \mathrm{mg} / \mathrm{dL} / \mathrm{min}$ vs. TAC, $p>0.05)$ or the AUCg $\left(55^{8} \pm 38 \mathrm{mg} / \mathrm{dL} / \mathrm{min}\right.$ vs. TAC, $\left.p>0.05\right)$ (Fig. 1).

\section{Effect of SK on TAC-induced histopathology in chronic TAC nephropathy}

Glomerular injury is a histological feature of chronic TAC nephropathy. TAC increased the fractional mesangial area $(17.3 \% \pm 2.4 \%$ vs. $5.8 \% \pm 1.0 \%, p<0.05)$ and decreased the number of WT-1-positive cells $(11.8 \pm 0.8$ vs. $22.8 \pm 1.6, p<0.05)$. SK treatment significantly reversed the fractional mesangial area $(12.1 \% \pm 1.8 \%$ vs. TAC, $p<$ $0.05)$ and the number of WT-1-positive cells (16.7 \pm 0.9 vs. TAC, $p<0.05$ ) (Fig. 2). TIF is a typical characteristic of chronic TAC nephropathy. TAC increased the TIF score $(11.8 \% \pm 2.5 \%$ vs. $0 \% \pm 0 \%, p<0.05)$ compared with that of the VH group, whereas SK decreased the TIF score $(4.6 \% \pm 0.8 \%$ vs. TAC, $p<0.05)$ compared with that of the TAC-treated group (Fig. 3).

\section{Effect of SK on TAC-induced inflammation in chron- ic TAC nephropathy}

ED-1-positive cells were rarely detected in the kidneys of $\mathrm{VH}$-treated rats $(0.6 \% \pm 0.1 \%)$. TAC treatment increased the number of ED-1-positve cells $(23.2 \pm 2.3$ vs. VH, $p<$ $0.05)$. Concomitant administration of SK significantly decreased the number of ED-1-positive cells $(15.1 \% \pm$ $2.1 \%$ vs. TAC, $p<0.05$ ) (Fig. 4). Immunohistochemistry to assess OPN levels revealed a dramatic increase in OPN expression in the TAC-treated group compared with the 


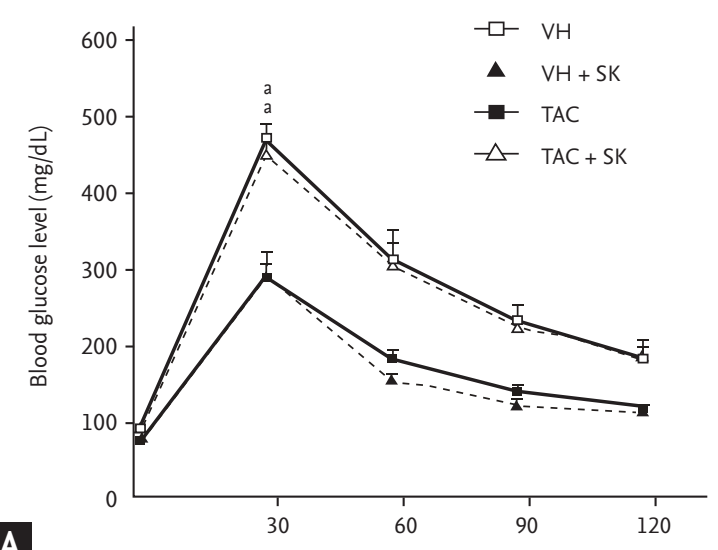

A

Figure 1. Blood glucose levels between treatment groups. (A) Intraperitoneal glucose tolerance test and (B) area under the curve of glucose (AUCg). VH, vehicle; SK, Shen-Kang; TAC, tacrolimus. ${ }^{\mathrm{a}} \mathrm{p}<0.05 \mathrm{vs} . \mathrm{VH},{ }^{\mathrm{b}} \mathrm{p}<0.05 \mathrm{vs}$. TAC.

A
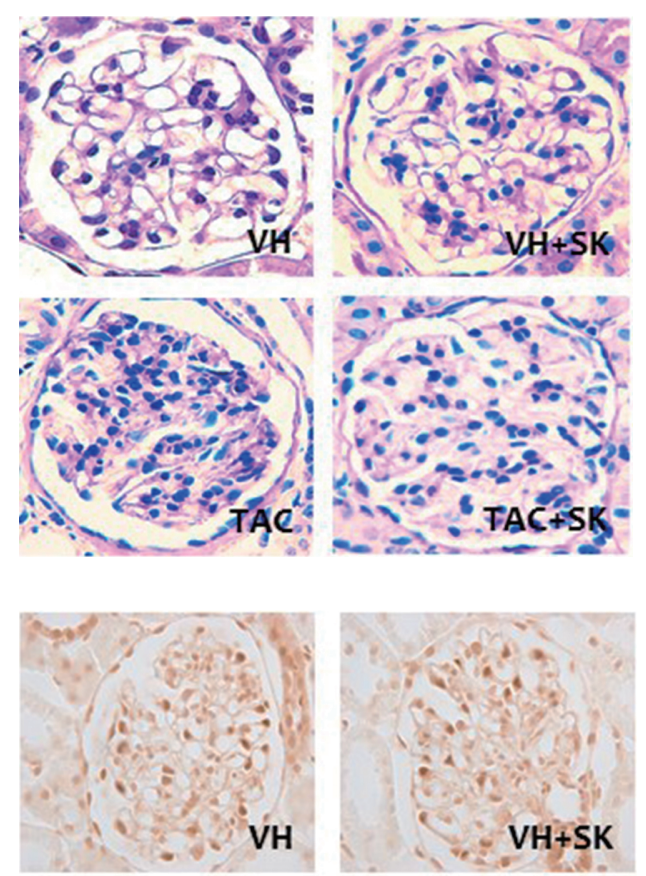

C

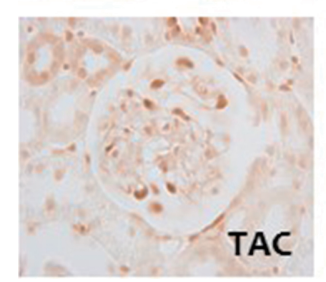

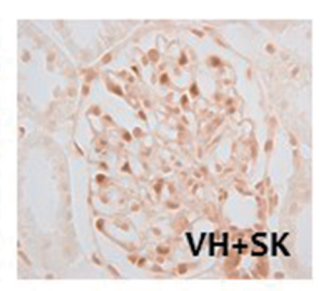

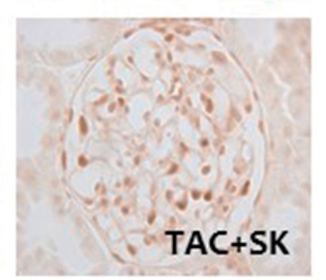

B

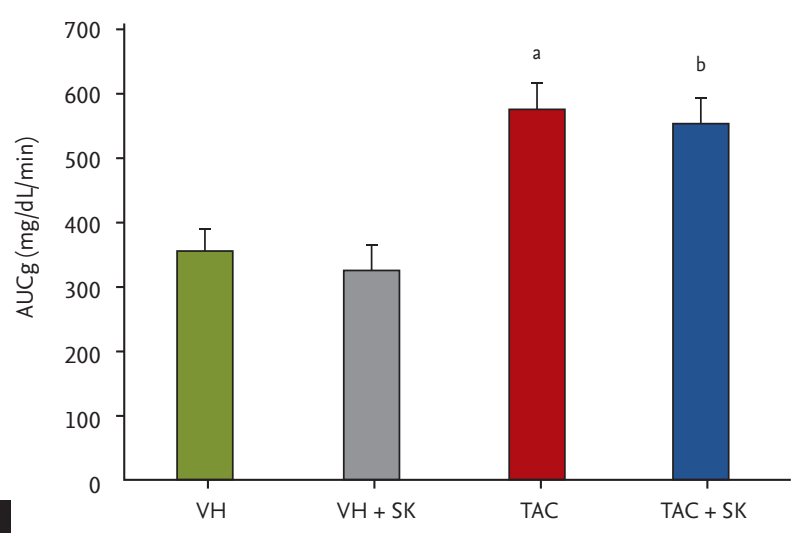



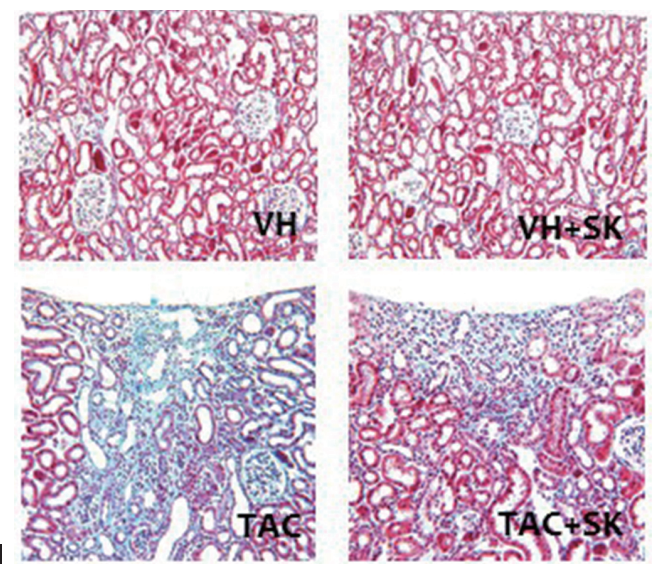

Figure 3. Representative photomicrographs of tubulointerstitial fibrosis (TIF) and semiquantitative analysis. (A) Trichrome staining ( $\times 40)$ and (B) semiquantitative analysis of TIF. VH, vehicle; SK, Shen-Kang; TAC, tacrolimus. ${ }^{\mathrm{a}} p<0.05$ vs. VH, ${ }^{\mathrm{b}} p<0.05$ vs. TAC.
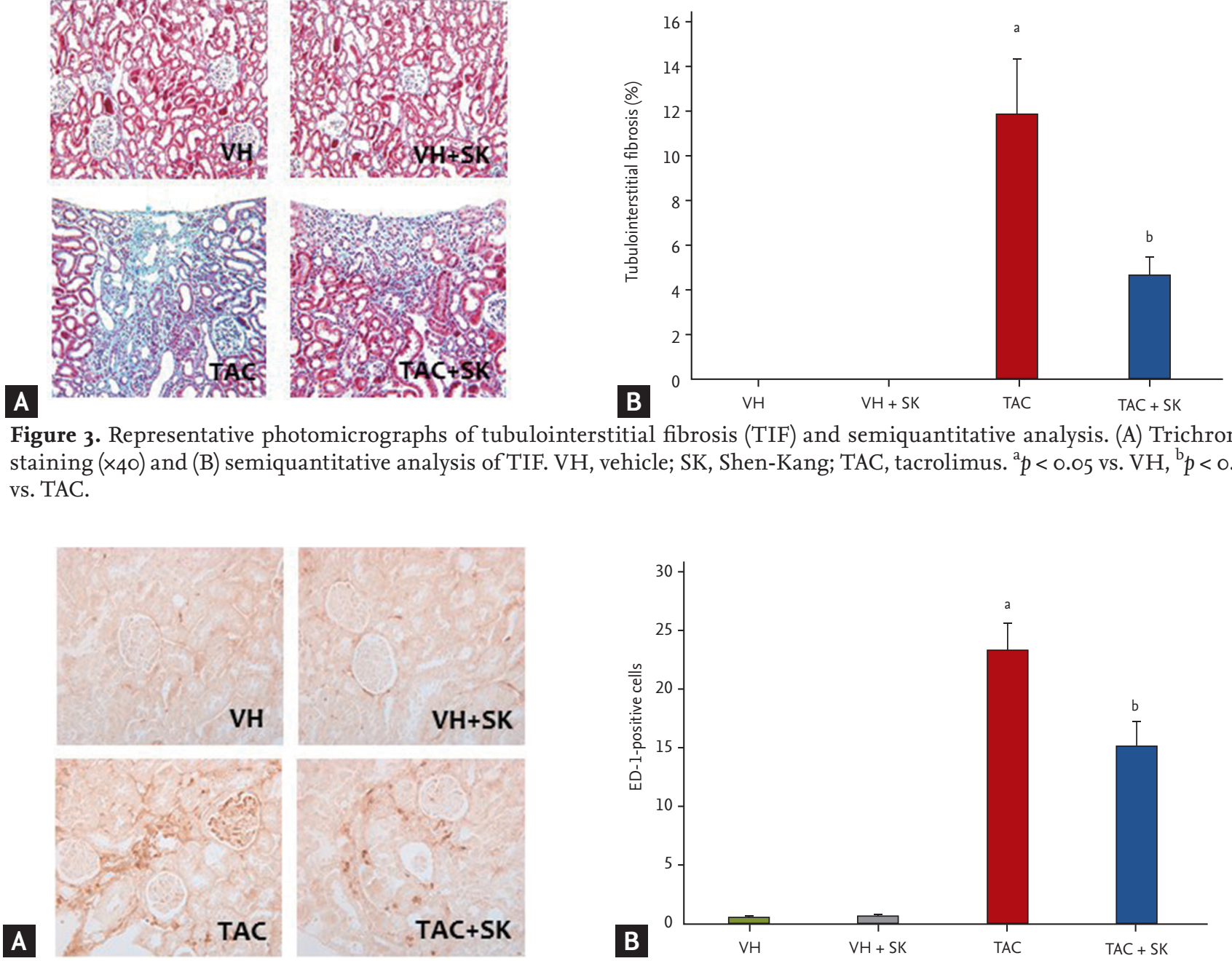

Figure 4. (A) Representative photomicrographs of immunohistochemistry for ectodermal dysplasia 1 (ED-1) ( $\times 200)$ and (B) semiquantitative analysis. VH, vehicle; SK, Shen-Kang; TAC, tacrolimus. ${ }^{a} p<0.05$ vs. VH, ${ }^{b}<<0.05$ vs. TAC.

IL-17 protein expression in the TAC group compared with the VH group $(150 \% \pm 12 \%$ vs. $100 \% \pm 10 \%, p<0.05)$, whereas SK significantly suppressed IL-17 expression $(120 \% \pm 11 \%$ vs. TAC, $p<0.05)$ (Fig. 5 B).

\section{Effect of SK on TGF- $\beta 1 / S_{2}$ mad2/3 signaling pathway and $\beta$ ig-h3 expression in chronic TAC nephropathy} The present study sought to compare the expression levels of the profibrotic cytokine TGF- $\beta 1 / \mathrm{Smad}_{2} / 3 \mathrm{sig}$ naling pathway and the extracellular matrix (ECM) component $\beta$ ig-h3 between treatment groups. The results of this study showed that TAC increased the levels of TGF- $\beta 1(160 \% \pm 11 \%$ vs. $102 \% \pm 9 \%, p<0.05)$ and phosphorylation $\operatorname{Smad} 2 / 3$ protein expression $(165 \% \pm 20 \%$ vs.
$100 \% \pm 9 \%, p<0.05)$ when compared with the $\mathrm{VH}$ (Fig. $6)$, whereas SK inhibited TGF- $\beta 1$ (104\% $\pm 5 \%$ vs. TAC, $p<$ $0.05)$ and phosphorylation Smad2/3 protein $(120 \% \pm 16 \%$ vs. TAC, $p<0.05)$ expression compared with TAC. As shown in Fig. 6, TAC treatment significantly increased Big-h3 expression compared with the VH group (230\% $\pm 25 \%$ vs. $99 \% \pm 10 \%, p<0.05)$, but this decreased significantly after SK co-treatment $(150 \% \pm 20 \%$ vs. TAC, $p$ $<0.05$ ).

\section{Effect of SK on Ang II in chronic TAC nephropathy} Intrarenal renin-angiotensin system (RAS) plays an important role in the pathogenesis of chronic TAC nephropathy [17]. Immunohistochemistry showed that 

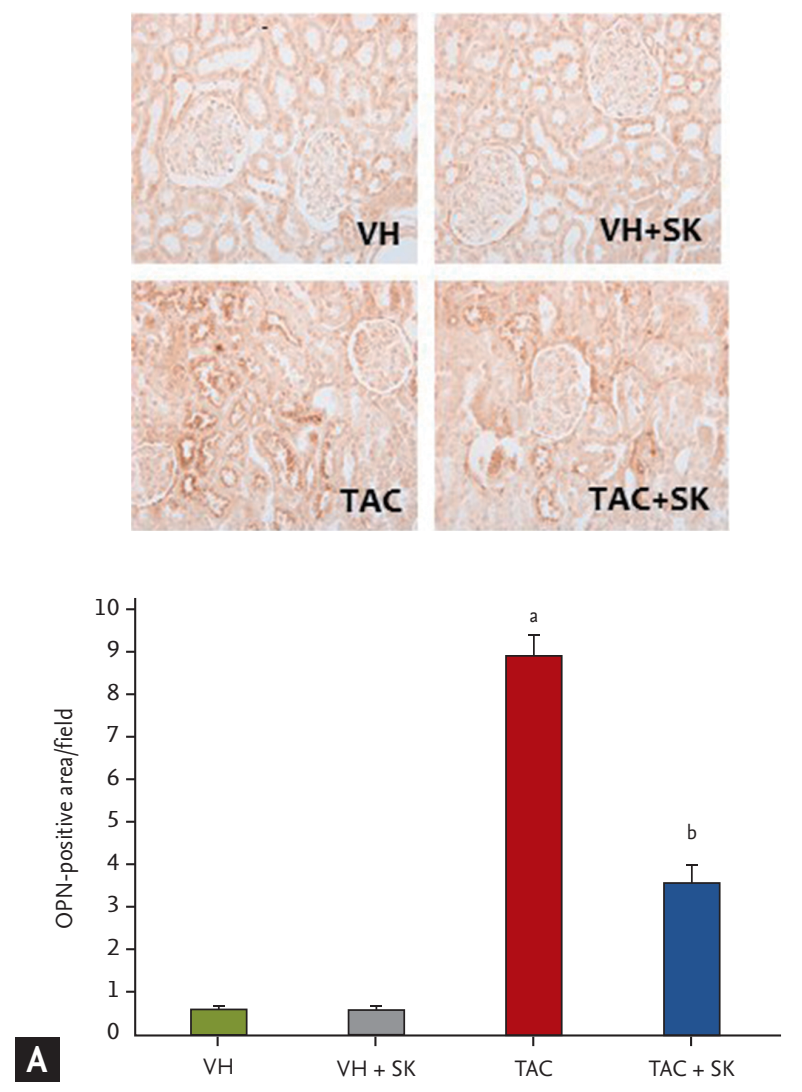

immunoreactivity of Ang II was increased in the TAC group compared with the $\mathrm{VH}$, which was confined to the juxtaglomerular afferent arterioles (Fig. 7). However, there was no immunoreactivity of Ang II in glomerular cells and tubular cells. Concomitant administration of SK significantly suppressed intrarenal Ang II activity. Using semiquantitative analysis, we found that Ang II-positive glomeruli increased in the TAC group $(62 \pm 6$ vs. $10 \pm 2, p<0.05)$, and this was reversed in the TAC + SK group (31 \pm 4 vs. TAC, $p<0.05)$.

\section{Effect of SK on oxidative stress in chronic TAC ne- phropathy}

Levels of 8-OHdG, a marker of oxidative stress, were much higher in the TAC-treated group than in the $\mathrm{VH}$ group in serum $(3.2 \pm 0.06 \mathrm{ng} / \mathrm{mL}$ vs. $1.6 \pm 0.05 \mathrm{ng} / \mathrm{mL}$, $p<0.05)$, urine $(23 \pm 14 \mathrm{ng} /$ day vs. $9.7 \pm 1.9 \mathrm{ng} /$ day, $p<$ $0.05)$, and the kidney $\left(15.6 \pm 2.2 \% / \mathrm{mm}^{2}\right.$ vs. $5.3 \pm 1.8 \% / \mathrm{mm}^{2}$, $p<0.05)$. SK considerably decreased 8-OHdG levels in serum $(1.8 \pm 0.03 \mathrm{ng} / \mathrm{mL}$ vs. TAC, $p<0.05)$, urine $(16.2 \pm$ $1.7 \mathrm{ng} /$ day vs. TAC, $p<0.05)$, and the kidney $(9.1 \pm 1.8 \% /$
B

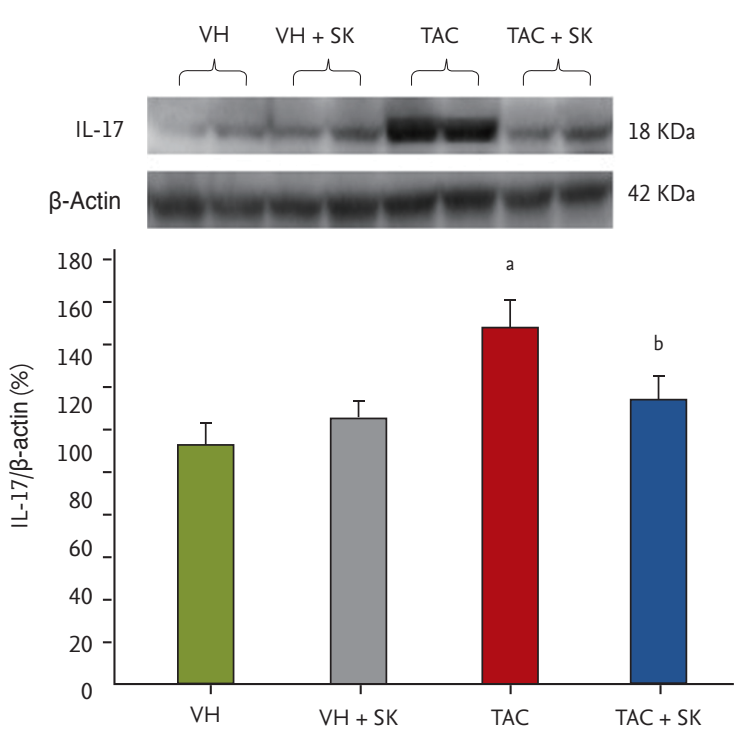

Figure 5. Representative photomicrographs of (A) immunohistochemistry for osteopontin (OPN) (×200) and (B) immunoblotting of interleukin 17 (IL-17). VH, vehicle; SK, ShenKang; TAC, tacrolimus. ${ }^{\mathrm{a}} \mathrm{p}<0.05$ vs. VH, ${ }^{\mathrm{b}} \mathrm{p}<0.05$ vs. TAC.

$\mathrm{mm}^{2}$ vs. TAC, $\left.p<0.05\right)$ compared with TAC (Fig. 8). In addition, we detected the expression of the antioxidant MnSOD in the kidneys by immunohistochemistry and immunoblotting. Immunohistochemistry revealed that most cortical structures, especially tubules, constitutively expressed MnSOD. In contrast, the expression and immunoreactivity of MnSOD were significantly suppressed in the tubules of the kidneys of TAC-treated rats (Fig. 9A). SK treatment preserved MnSOD expression. Immunoblotting consistently showed that MnSOD expression decreased in the kidneys of TAC-treated rats compared with those of $\mathrm{VH}$ rats by approximately $50 \%(52 \% \pm 10 \%$ vs. $103 \% \pm 8 \%, p<0.05)$, whereas this suppression was reversed by concomitant treatment with $\mathrm{SK}$ and remained at normal levels $(109 \% \pm 5 \%$ vs. TAC, $p<0.05)$ (Fig. $9 \mathrm{~B})$.

\section{Effect of SK on apoptotic cell death in chronic TAC nephropathy}

In this study, we examined renal cell apoptosis and the expression of related genes in the kidney, because this process plays a critical role in chronic TAC-induced ne- 


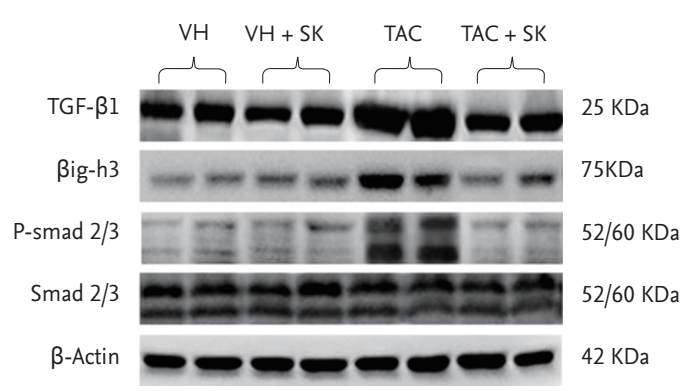

A

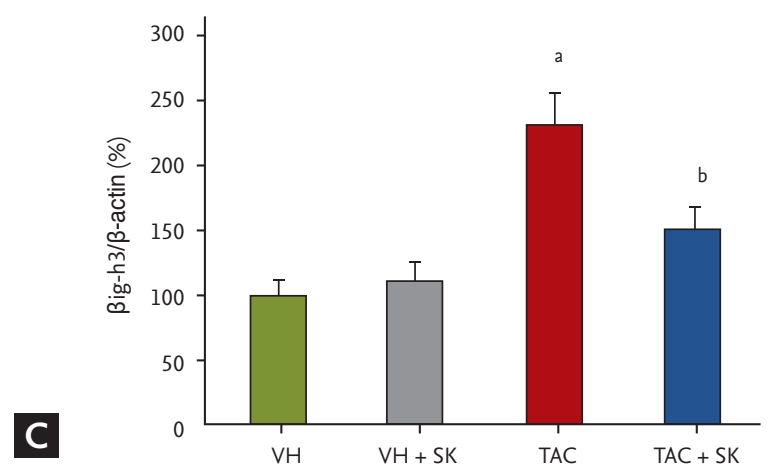

B

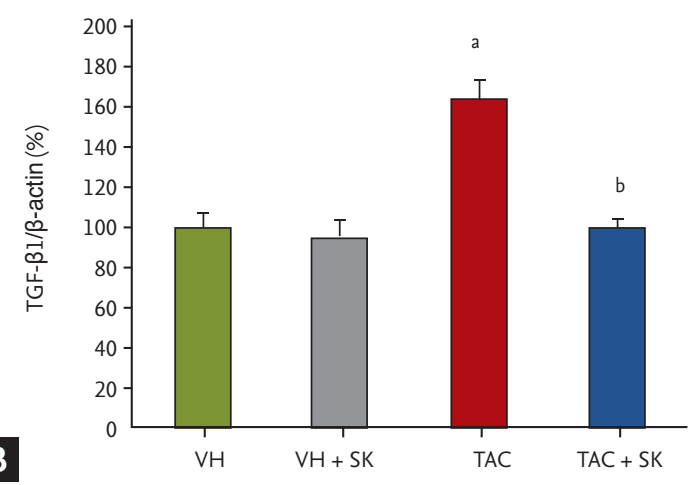

D

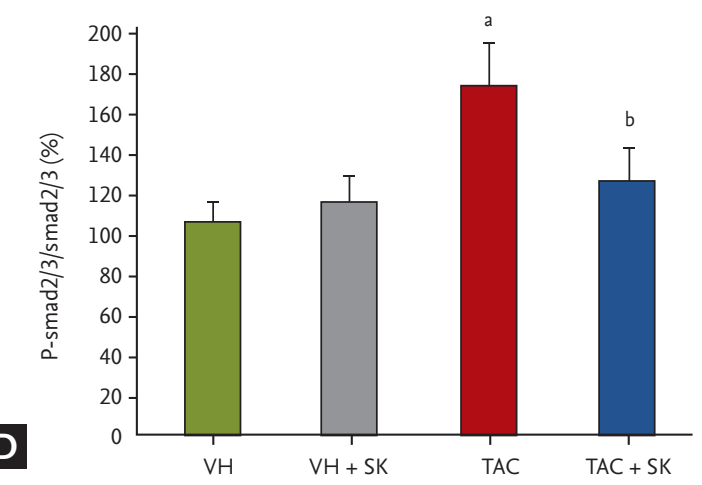

Figure 6. (A) Immunoblotting of (B) transforming growth factor $\beta_{1}$ (TGF- $\beta_{1}$ ), (C) Smad2/3, and (D) inducible gene-h3 ( Sig-h3) $_{3}$ and quantitative analysis. $\mathrm{VH}$, vehicle; SK, Shen-Kang; TAC, tacrolimus. ${ }^{\mathrm{a}} \mathrm{p}<0.05 \mathrm{vs}$. VH, ${ }^{\mathrm{b}} \mathrm{p}<0.05$ vs. TAC.
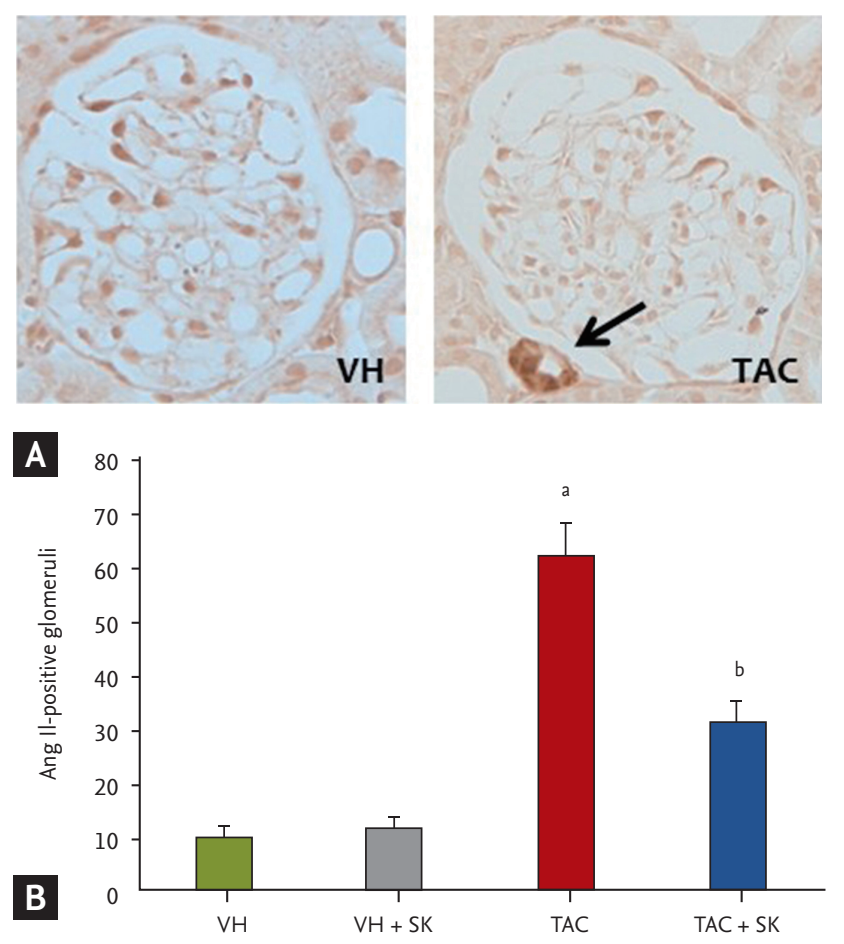

Figure 7. Representative photomicrographs of immunohistochemistry for (A) angiotensin II (Ang II) (×400) and (B) semiquantitative analysis (arrow). VH, vehicle; SK, Shen-Kang; TAC, tacrolimus. ${ }^{\mathrm{a}} \mathrm{p}<0.05 \mathrm{vs}$. VH, ${ }^{\mathrm{b}} \mathrm{p}<0.05 \mathrm{vs}$. TAC. phropathy. By using a TUNEL assay, we found that TAC significantly increased the number of TUNEL-positive cells compared with the $\mathrm{VH}\left(10.2 \pm 2.0\right.$ cell $/ \mathrm{mm}^{2}$ vs. 0.6 $\left.\pm 0.1 \mathrm{cell} / \mathrm{mm}^{2}, p<0.05\right)$. Consistent with previous studies $[18,19]$, most TUNEL-positive cells were localized to tubules and interstitium, where severe TIF and tubular atrophy had developed (Fig. 10A). The concomitant administration of SK to rats markedly reduced the number of TUNEL-positive cells compared with the result seen in the TAC group $\left(4.6 \pm 1.8 \mathrm{cell} / \mathrm{mm}^{2} \mathrm{vs}\right.$. TAC, $\left.p<0.05\right)$. At a molecular level, SK treatment modulated the expression of apoptosis-related genes in favor of cell survival, which included an increase in the Bcl-2/Bax ratio (103\% $\pm 2 \%$ vs. $65 \% \pm 6 \%, p<0.05)$ and a decrease in the number of caspase-3-positive cells ( $3.6 \% \pm 0.4 \%$ vs. $8.1 \% \pm 0.4 \%, p$ $<0.05$ ) (Figs. 10B and 11).

\section{DISCUSSION}

Chronic TAC nephropathy contributes to the risk of end-stage renal disease requiring maintenance dialysis, 

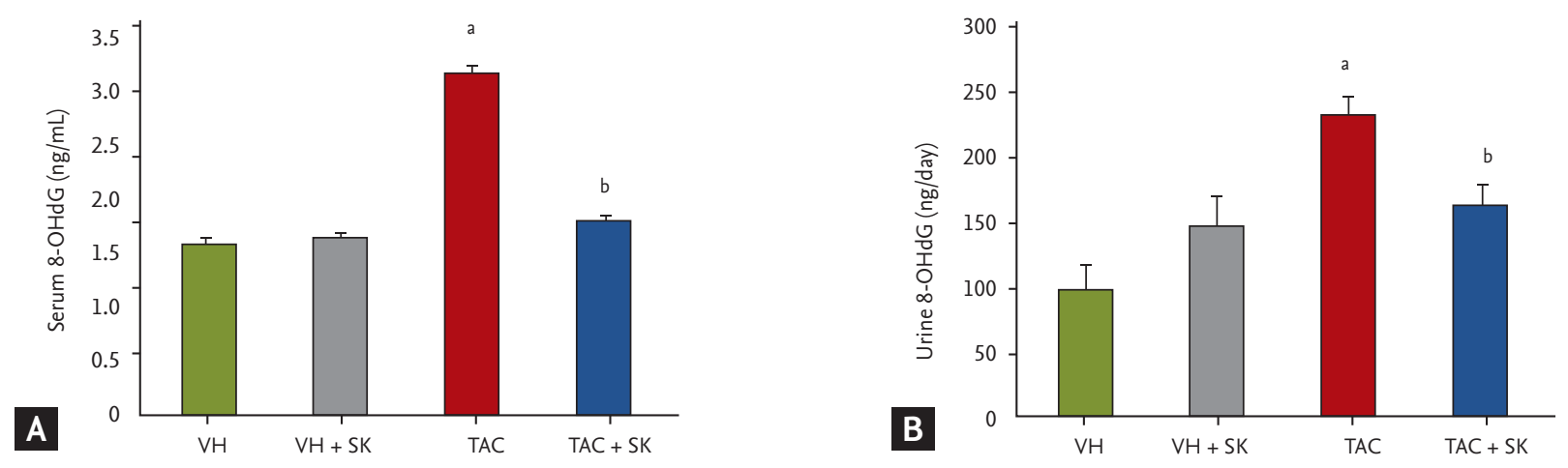

C

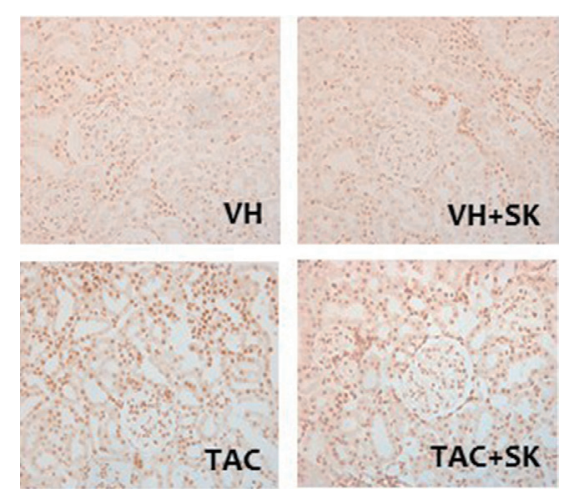

Figure 8. 8-Hydroxy-2'-deoxyguanosine (8-OhdG) levels in (A) serum, (B) urine, and (C, D) the kidney (immunohistochemical staining, $\times 200)$. VH, vehicle; SK, Shen-Kang; TAC, tacrolimus. ${ }^{\mathrm{a}} \mathrm{p}<0.05 \mathrm{vs} . \mathrm{VH},{ }^{\mathrm{b}} \mathrm{p}<0.05 \mathrm{vs}$. TAC.
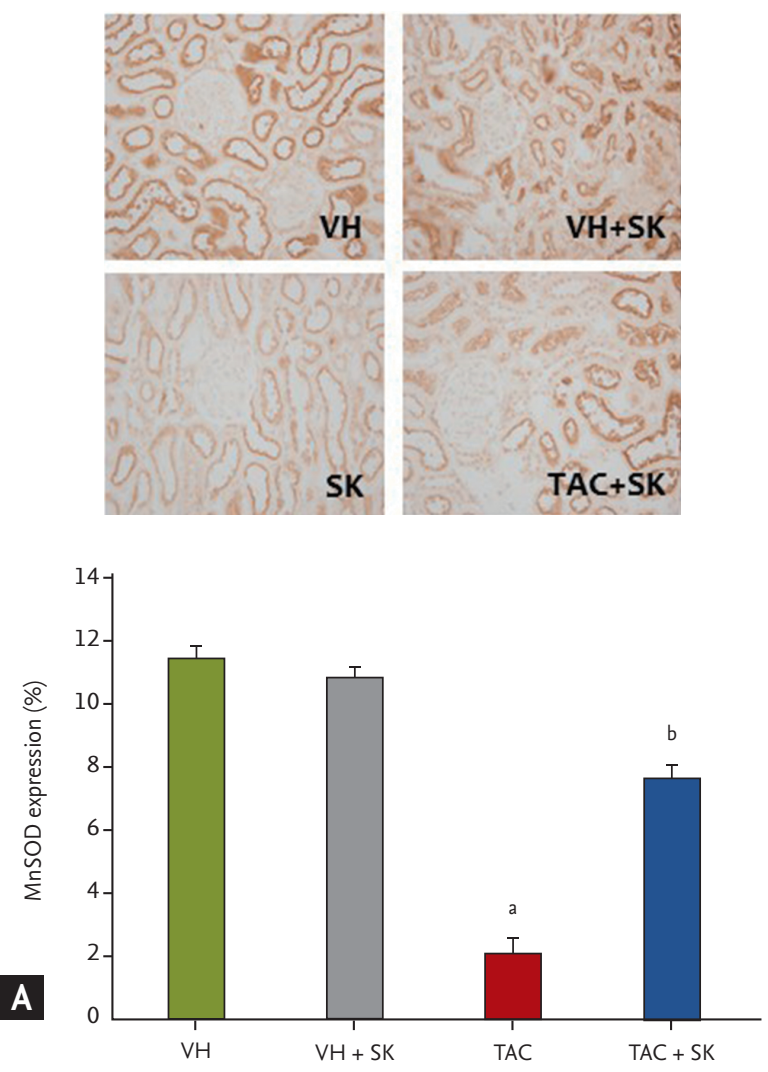
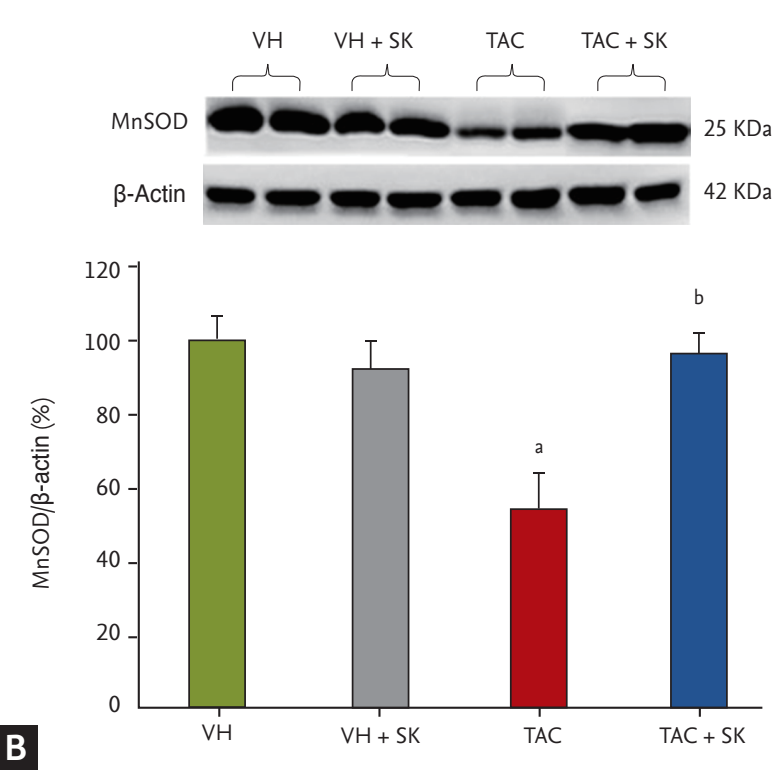

Figure 9. (A) Immunohistochemistry and (B) immunoblotting of manganese superoxide dismutase (MnSOD) (immunohistochemical staining, $\times 200)$. VH, vehicle; SK, ShenKang; TAC, tacrolimus. ${ }^{a} p<0.05$ vs. VH, ${ }^{b} p<0.05$ vs. TAC. 

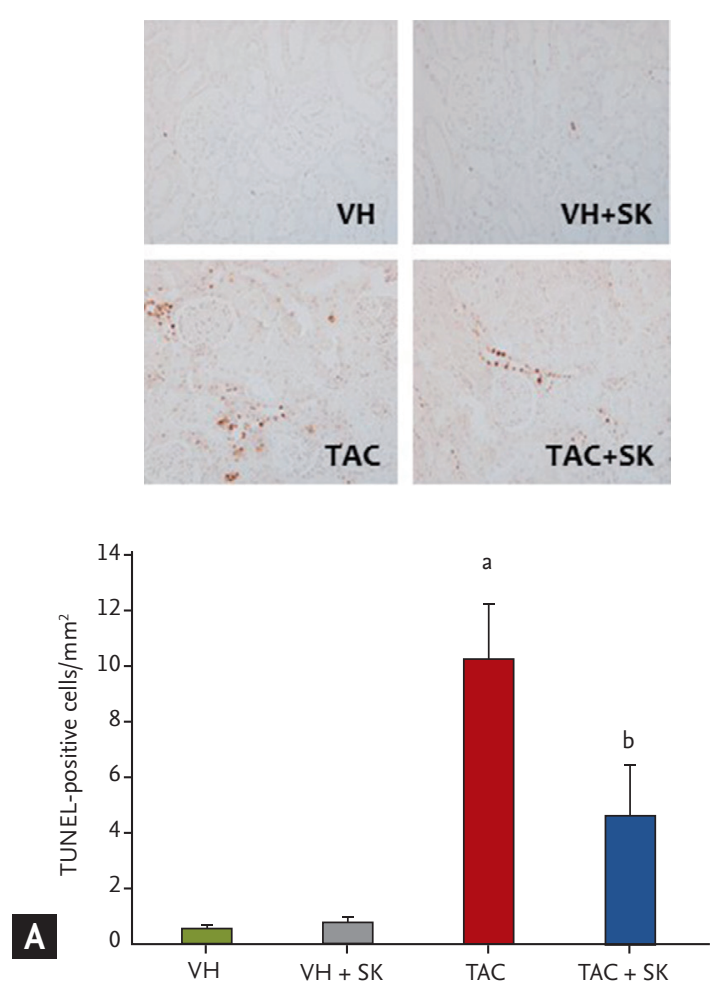
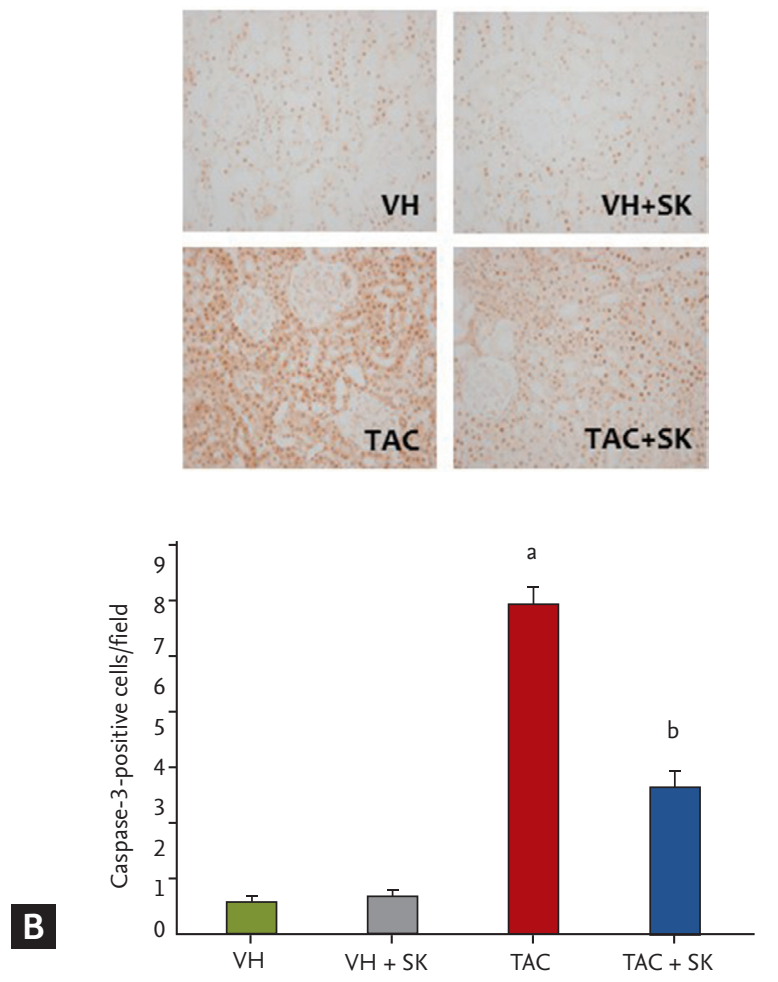

Figure 10. Representative photomicrographs of (A) terminal deoxynucleotidyl transferase-mediated dUTP nick-end labeling (TUNEL) assay and (B) immunohistochemistry for caspase-3 (×200). VH, vehicle; SK, Shen-Kang; TAC, tacrolimus. ${ }^{\mathrm{a}} \mathrm{p}<0.05 \mathrm{vs}$. $\mathrm{VH},{ }^{\mathrm{b}} \mathrm{p}<0.05 \mathrm{vs}$. TAC.

and increases over time in renal and nonrenal transplant recipients. Thus, reducing this complication represents an important therapeutic strategy. This study clearly showed that SK treatment prevented glomerular and tubulointerstitial injury in the kidneys of TAC-treated rats, and this histological improvement was accompanied by recovery from renal dysfunction and proteinuria. Our results expand the known roles of the traditional Chinese herbal medicine SK to the prevention of TAC-induced renal injury.

Inflammation is critical in the development of chronic TAC nephropathy, which precedes TIF, and several proinflammatory mediators are involved in this process. OPN is a potent chemotactic and adhesive factor for macrophages, and increasing evidence has confirmed that the upregulation of tubular OPN expression is strongly associated with macrophage infiltration subsequent to tubulointerstitial injury in chronic TAC nephropathy [20]. This concept is supported by data on OPN-gene knockout mice and antisense-treated or anti-OPN antibody-treated animals that demonstrated a significant reduction in macrophage influx and renal architecture impairment $[21,22]$. We have recently revealed that overexpression of OPN plays a pathological role in TAC-induced renal injury $[3,5]$. Recently, increasing evidence suggests that IL17 triggers a renal inflammatory response in the kidneys of diabetes $[23,24]$. In this study, we anticipated that SK would attenuate tubulointerstitial inflammation caused by TAC because SK inhibits inflammatory mediators (C-reactive protein, tumor necrosis factor $\alpha$, and IL-6) in a rat model of hypertensive renal damage and decreases renal interstitial CD68+ cell infiltration in STZ-induced diabetic rats fed a high-sugar and high-fat diet [10,11] Our results showed that SK treatment downregulated renal OPN and IL-17 expression, leading to a reduction in the number of ED-1-positive cells. This finding implies that SK possesses an anti-inflammatory property in chronic TAC nephropathy.

Unlike cyclosporine nephropathy, chronic TAC nephropathy is manifested by typical histological features including not only striped TIF but also glomerular injury. As a result, chronic TAC nephropathy involves both re- 

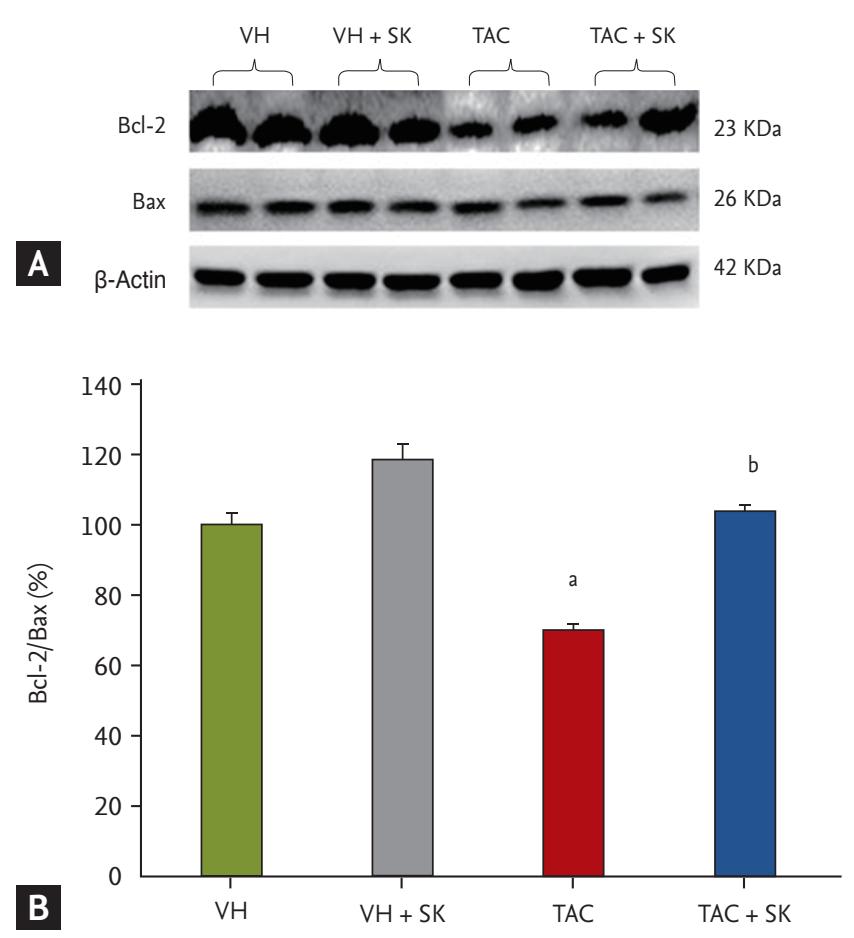

Figure 11. (A) Immunoblotting of B-cell lymphoma-2 (Bcl-2) and $\mathrm{Bcl}$-associated $\mathrm{X}(\mathrm{Bax})$ and $(\mathrm{B})$ quantitative analysis of the Bcl-2/Bax ratio. VH, vehicle; SK, Shen-Kang; TAC, tacrolimus. ${ }^{\mathrm{a}} \mathrm{p}<0.05 \mathrm{vs}$. VH, ${ }^{\mathrm{b}} \mathrm{p}<0.05 \mathrm{vs}$. TAC.

nal dysfunction and proteinuria [3]. It is well known that TGF- $\beta 1$ plays a pivotal role in renal scarring in a wide range of kidney diseases probably by its action on ECM synthesis and degradation [25-27]. It has been confirmed by in vivo and in vitro studies that TAC induces TGF- $\beta 1$ expression either directly or indirectly. TAC may act directly to stimulate TGF- $\beta 1$ secretion in human renal proximal tubule epithelial cells [28]. However, TAC may also induce TGF- $\beta 1$ indirectly through activation of the RAS $[3,29]$. In this study, we found that the upregulated expression of TGF- $\beta 1 / p-S m a d 2 / 3$ and the ECM component $\beta$ ig-h 3 in the kidneys of the TAC-treated rats was significantly decreased after SK treatment, and this was accompanied by improved renal dysfunction and urine albumin excretion. Moreover, SK treatment significantly decreased the number of Ang II-positive glomeruli. In addition to TIF, SK decreased the glomerular mesangial fractional area, increased the number of podocytes, and preserved foot process structure. These findings are consistent with our previous studies and suggest that SK is effective in protecting against TAC-induced renal injury.

Many mechanisms may account for the antiinflammato- ry and antifibrotic effects of SK in chronic TAC nephropathy, and the involvement of oxidative stress and apoptotic cell death should be considered. Short- and long-term TAC treatment is associated with afferent arteriolopathy-related hypoxia, which ultimately results in oxidative stress-induced tubulointerstitial inflammation and renal injury [3,5]. SK elicits antifibrosis and antioxidation in a CKD model established by $5 / 6$ nephrectomy and puromycin aminonucleoside-induced nephrosis $[8,30]$. In addition, apoptotic cell death plays an important role in TAC-induced renal damage because TAC induces renal cell apoptosis in vivo and in vitro [18,31,32]. Liu et al. [6] reported that SK treatment significantly prevented renal proximal tubule epithelial cells (HK-2 cells) from hydrogen peroxide-induced apoptosis. The results of this study showed that SK decreased 8-OHdG levels in serum, urine, and the kidney, and increased antioxidant MnSOD production. Moreover, SK reduced the number of TUNEL-positive cells and modulated apoptosis-related genes (caspase- 3 and the Bcl-2/Bax ratio) that favor cell survival. Indeed, the protective effect of SK on TAC-treated kidneys in this study may be, in part, related to its actions on oxidative stress and apoptosis.

In clinical practice, SK injection has been routinely applied to treat stage 1 to stage 3 CKD patients in China without adverse side effects. However, the molecular mechanism underlying the renoprotective effect of SK is rarely explored. In recent reports, SK has been found to protect against renal injury in animal models of 5/6 nephrectomy and STZ-induced DN through its antioxidant and antifibrotic potential $[9,10]$. In this study, we showed antiinflammatory and antiapoptotic effects of SK in TAC-induced renal injury. Therefore, SK elicits protective effects in the kidney owing to its antioxidant and antiapoptotic properties. Of note, SK improved renal dysfunction and proteinuria, but it failed to influence blood glucose level as measured by IPGTT and AUCg, which was increased in TAC-treated rats. This observation suggests that, although SK did not affect DM caused by TAC, it was still effective in preventing chronic TAC-induced nephropathy.

In summary, this study demonstrates that SK offers antiinflammatory and antifibrotic effects in a rat model of chronic TAC nephropathy. Suppression of oxidative stress and apoptotic cell death may be one of the mechanisms underlying the renoprotective properties 
of SK. Our findings provide a potential rationale for the clinical use of SK in reducing chronic TAC-induced nephropathy.

\section{KEY MESSAGE}

1. Shen-Kang protects against glomerular injury by decreasing fractional mesangial area and preserving podocyte number.

2. Shen-Kang protects against tubulointerstitial inflammation and fibrosis by suppressing osteopontin, interleukin 17 , transforming growth factor $\beta 1 / \mathrm{Smad}_{2} / 3$, and $\beta$ ig-h3 (inducible gene-h3) expression.

3. Shen-Kang inhibits renal cell apoptosis through decreasing caspase-3 expression and upregulating the B-cell lymphoma-2/Bcl2-associated X (Bcl-2/ Bax) ratio.

4. Shen-Kang suppresses oxidative stress through decreasing 8-hydroxy-2'-deoxyguanosine levels and restoring manganese superoxide dismutase production.

\section{Conflict of interest}

No potential conflict of interest relevant to this article was reported.

\section{Acknowledgments}

This work was supported by the National Natural Science Foundation of China (No. 81560125), the Korean Health Technology R\&D project, Ministry for Health and Welfare, Republic of Korea (HI14C3417), and Basic Science Research Program through the National Research Foundation of Korea (NRF) funded by the Ministry of Science, ICT \& Future Planning (NRF-2015R1A1A3Ao400946). We thanks the Xi'an Shiji ShengKang Pharmaceutical Industry Co. Ltd. of China kindly provided Shen-Kang injection and financially supported to this study.

\section{REFERENCES}

1. Lim SW, Jin JZ, Jin L, Jin J, Li C. Role of dipeptidyl peptidase-4 inhibitors in new-onset diabetes after transplantation. Korean J Intern Med 2015;30:759-770.
2. Stratta P, Canavese C, Quaglia M, et al. Posttransplantation chronic renal damage in nonrenal transplant recipients. Kidney Int 2005;68:1453-1463.

3. Jin J, Jin L, Luo K, Lim SW, Chung BH, Yang CW. Effect of empagliflozin on tacrolimus-induced pancreas islet dysfunction and renal injury. Am J Transplant 2017;17:26012616.

4. Jin J, Lim SW, Jin L, et al. Effects of metformin on hyperglycemia in an experimental model of tacrolimus- and sirolimus-induced diabetic rats. Korean J Intern Med 2017;32:314-322.

5. Lim SW, Jin L, Piao SG, Chung BH, Yang CW. Inhibition of dipeptidyl peptidase IV protects tacrolimus-induced kidney injury. Lab Invest 2015;95:1174-1185.

6. Liu M, Park J, Wu X, et al. Shen-Kang protects 5/6 nephrectomized rats against renal injury by reducing oxidative stress through the MAPK signaling pathways. Int J Mol Med 2015;36:975-984.

7. Xu S, Lv Y, Zhao J, Wang J, Zhao X, Wang S. Inhibitory effects of Shenkang injection and its main component emodin on the proliferation of high glucose-induced renal mesangial cells through cell cycle regulation and induction of apoptosis. Mol Med Rep 2016;14:3381-3388.

8. Wu X, Guan Y, Yan J, et al. ShenKang injection suppresses kidney fibrosis and oxidative stress via transforming growth factor- $\beta / \operatorname{mad}_{3}$ signalling pathway in vivo and in vitro. J Pharm Pharmacol 2015;67:1054-1065.

9. Zhang YU, Zhou N, Wang H, Wang S, He J. Effect of Shenkang granules on the progression of chronic renal failure in 5/6 nephrectomized rats. Exp Ther Med 2015;9:20342042.

10. Liu Y, Ma Q, Yang G, et al. Early renal tubulointerstitial changes and their interventions with Shenkang Injection in diabetic rats. Zhonghua Yi Xue Za Zhi 2015;95:289-293.

11. Zhang Y, Zhou N, Li T, Wang HY, He JY. Effect of Shenkang Injection on kidney function in hypertensive renal damage rats. Zhong Yao Cai 2014;37:2248-2254.

12. Jin L, Lim SW, Doh KC, et al. Dipeptidyl peptidase IV inhibitor MK-0626 attenuates pancreatic islet injury in tacrolimus-induced diabetic rats. PLoS One 2014;9:e100798.

13. Piao SG, Bae SK, Lim SW, et al. Drug interaction between cyclosporine and mTOR inhibitors in experimental model of chronic cyclosporine nephrotoxicity and pancreatic islet dysfunction. Transplantation 2012;93:383-389.

14. Chung BH, Li C, Sun BK, et al. Rosiglitazone protects against cyclosporine-induced pancreatic and renal injury 
in rats. Am J Transplant 2005:5:1856-1867.

15. Li C, Yang CW, Park JH, et al. Pravastatin treatment attenuates interstitial inflammation and fibrosis in a rat model of chronic cyclosporine-induced nephropathy. Am J Physiol Renal Physiol 2004;286:F46-F57.

16. Lim SW, Doh KC, Jin L, et al. Ginseng treatment attenuates autophagic cell death in chronic cyclosporine nephropathy. Nephrology (Carlton) 2014;19:490-499.

17. Al-Harbi NO, Imam F, Al-Harbi MM, et al. Olmesartan attenuates tacrolimus-induced biochemical and ultrastructural changes in rat kidney tissue. Biomed Res Int 2014;2014:607246.

18. Jin J, Jin L, Lim SW, Yang CW. Klotho deficiency aggravates tacrolimus-induced renal injury via the phosphatidylinositol 3-kinase-Akt-Forkhead box protein o pathway. Am J Nephrol 2016;43:357-365.

19. Li C, Lim SW, Sun BK, et al. Expression of apoptosis-related factors in chronic cyclosporine nephrotoxicity after cyclosporine withdrawal. Acta Pharmacol Sin 2004;25:401411.

2o. Khanna A. Tacrolimus and cyclosporinein vitro and in vivo induce osteopontin mRNA and protein expression in renal tissues. Nephron Exp Nephrol 2005;101:e119-e126.

21. Ophascharoensuk V, Giachelli CM, Gordon K, et al. Obstructive uropathy in the mouse: role of osteopontin in interstitial fibrosis and apoptosis. Kidney Int 1999;56:571580.

22. Yu XQ, Nikolic-Paterson $\mathrm{DJ}, \mathrm{Mu} \mathrm{W}$, et al. A functional role for osteopontin in experimental crescentic glomerulonephritis in the rat. Proc Assoc Am Physicians 1998;110:5064.

23. Seo JW, Kim YG, Lee SH, et al. Mycophenolate mofetil ameliorates diabetic nephropathy in $\mathrm{db} / \mathrm{db}$ mice. Biomed Res Int 2015;2015:301627.

24. Kuo HL, Huang CC, Lin TY, Lin CY. IL-17 and CD40 ligand synergistically stimulate the chronicity of diabetic nephropathy. Nephrol Dial Transplant 2018;33:248-256.

25. Kim JY, Lim SW, Li C, et al. Effect of FTY720 on chronic cyclosporine nephropathy in rats. Transplantation 2005;80:1323-1330.

26. Shen Y, Miao NJ, Xu JL, et al. N-acetylcysteine alleviates angiotensin II-mediated renal fibrosis in mouse obstructed kidneys. Acta Pharmacol Sin 2016;37:637-644.

27. Jin H, Piao SG, Jin JZ, et al. Synergistic effects of leflunomide and benazepril in streptozotocin-induced diabetic nephropathy. Nephron Exp Nephrol 2014;126:148-156.

28. Bennett J, Cassidy H, Slattery C, Ryan MP, McMorrow T. Tacrolimus modulates TGF- $\beta$ signaling to induce epithelial-mesenchymal transition in human renal proximal tubule epithelial cells. J Clin Med 2016;5:E50.

29. Agirbasli M, Papila-Topal N, Ogutmen B, et al. The blockade of the renin-angiotensin system reverses tacrolimus related cardiovascular toxicity at the histopathological level. J Renin Angiotensin Aldosterone Syst 2007;8:54-58.

30. Liu X, Liu Y, Yang Y, et al. Antioxidative stress effects of Salvia przewalskii extract in experimentally injured podocytes. Nephron 2016;134:253-271.

31. Hisamura F, Kojima-Yuasa A, Kennedy DO, Matsui-Yuasa I. Protective effect of green tea extract and tea polyphenols against FK506-induced cytotoxicity in renal cells. Basic Clin Pharmacol Toxicol 2006;98:192-196.

32. Kim HS, Lim SW, Jin L, Jin J, Chung BH, Yang CW. The protective effect of febuxostat on chronic tacrolimus-induced nephrotoxicity in rats. Nephron 2017;135:61-71. 